\title{
Thermoablation of Bone Tumors
}

\section{Thermoablation von Knochentumoren}

Authors

Affiliations
K. I. Ringe ${ }^{1}$, M. Panzica ${ }^{2}$, C. von Falck ${ }^{1}$

Department of Diagnostic and Interventional Radiology, Medizinische Hochschule Hannover, Germany

2 Department of Trauma Surgery, Medizinische Hochschule Hannover, Germany

Key words
bones
laser
RFA
MWA
cryoablation
HIFU

received $\quad 15.10 .2015$

accepted 26.12.2015

Bibliography

DOI http://dx.doi.org/

10.1055/s-0042-100477

Published online: 16.3.2016

Fortschr Röntgenstr 2016; 188 :

539-550 @ Georg Thieme

Verlag KG Stuttgart - New York ·

ISSN 1438-9029

\section{Correspondence}

\section{Dr. Kristina Imeen Ringe}

Institut für Diagnostische und Interventionelle Radiologie,

Medizinische Hochschule

Hannover

Carl-Neuberg Straße 1

30625 Hannover

Germany

Tel.: ++ 49/5 11/5323424

Fax: $++49 / 511 / 5329421$

ringe.kristina@mh-hannover.de

\section{Abstract \\ $\nabla$}

The aim of this article is to review the significance of percutaneous thermal ablation in the treatment of bone tumors. We describe available ablation techniques as well as advantages and disadvantages in specific settings. In detail, radiofrequency ablation (RFA), microwave ablation (MWA), laser ablation, high intensity focused ultrasound (HIFU) and cryoablation are presented. In the second part of this review curative and palliative indications for the treatment of benign and malignant bone tumors are discussed. This includes especially RFA, laser or cryoablation for the treatment of osteoid osteoma, as well as the palliative treatment of painful bone metastases, for example, by means of MWA or MR-guided HIFU.

Key Points:

- The various thermoablative techniques demonstrate specific advantages and disadvantages.

- Radiofrequency ablation is the evidencebased method of choice for treating osteoid osteoma.

- Laser ablation is primarily suited for the treatment of small lesions of the hands and feet.

- The intrinsically analgesic effect of cryoablation is advantageous when treating painful lesions.

- Palliative treatment of painful bone metastases can for example be performed using MWA or MR-guided HIFU, by itself or combined with cementoplasty.

Citation Format:

- Ringe KI, Panzica M, von Falck C. Thermoablation of Bone Tumors. Fortschr Röntgenstr 2016; 188: 539-550

\section{Zusammenfassung \\ $\nabla$}

In der vorliegenden Übersichtsarbeit wird der Stellenwert der perkutanen Thermoablation bei der Behandlung von Knochentumoren dargelegt. Zunächst werden technische Grundlagen der unterschiedlichen Verfahren beschrieben, sowie Vorund Nachteile der einzelnen Methoden aufgezeigt. Im Detail wird dabei auf die Radiofrequenzablation (RFA), die Mikrowellenablation (MWA), die Laserablation, den hochintensiven fokussierten Ultraschall (HIFU) sowie die Kryoablation eingegangen. Im zweiten Abschnitt werden kurative und palliative Indikationen zur Behandlung benigner und maligner Knochenläsionen diskutiert. Hierzu zählen insbesondere die RFA, Laser- oder Kryoablation zur Behandlung des Osteoidosteoms, sowie die palliative Behandlung schmerzhafter Knochenmetastasen beispielsweise mittels MWA oder MRgesteuertem HIFU.

\section{Introduction}

Image-guided percutaneous ablation is a well-established treatment method for primary and secondary tumors of parenchymatous abdominal organs, the lungs, and the musculoskeletal system. Chemical treatment methods have been distinguished from energy-based methods, based on the recommendations of the International Working Group on Image-Guided Tumor Ablation, which was developed in conjunction with the Cardiovascular and Interventional Radiological Society of Europe (CIRSE) [1]. Thermoablative techniques are the treatment of choice for ablation of tumors of the musculoskeletal system (० Fig. 1).

The goal of all thermoablative procedures is to induce coagulation necrosis in the target tissue using special applicators (electrodes, 


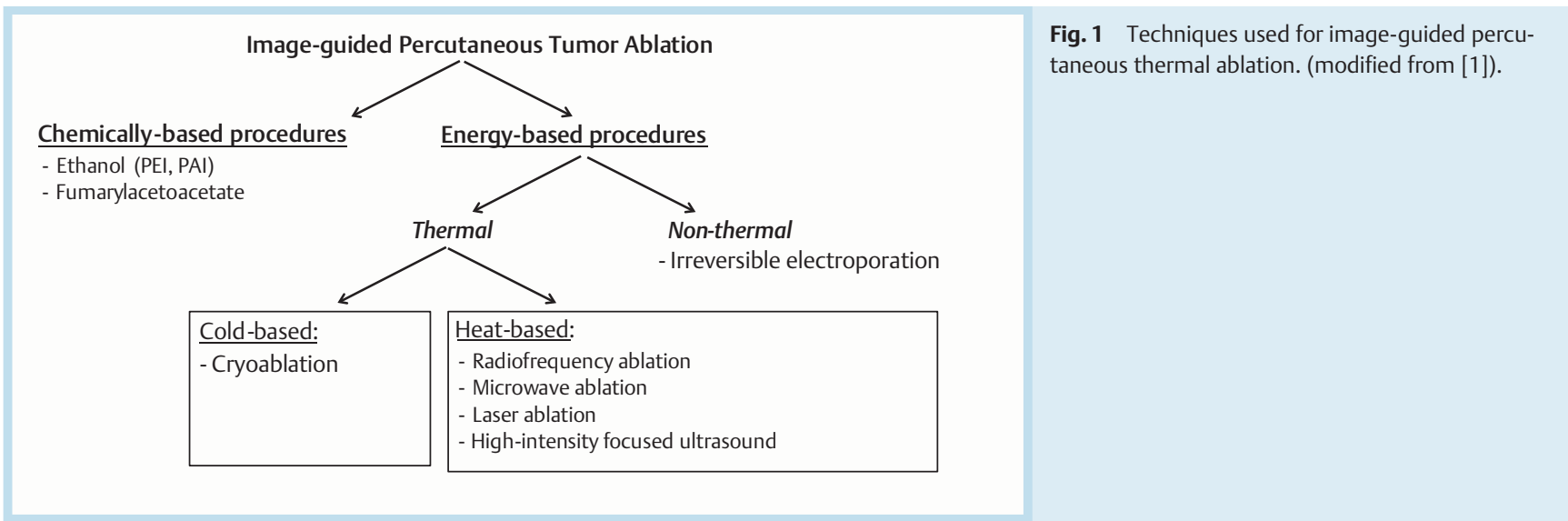

antennas, probes) placed in the tumor using image guidance. Depending on the procedure, the tissue is either cooled to below $-20^{\circ} \mathrm{C}$ (cryoablation) or heated to temperatures above $80^{\circ} \mathrm{C}$ (hyperthermal ablation). The latter technique includes radiofrequency ablation (RFA), microwave ablation (MWA), laser ablation and high-intensity focused ultrasound (HIFU). During thermal ablation, the extent of coagulation necrosis is dependent upon three important factors: 1 . The quantity of applied energy, 2. Local tissue interactions, 3. Losses of heating or cooling effects (most significant is the so-called heat sink effect) [2]. The individual techniques exhibit specific advantages and disadvantages that will be described in more detail below. Selection of the imaging method for placing the applicators depends on the method of treatment, the operator's preference as well as the availability of equipment. Computed tomography (CT) or magnetic resonance imaging (MRI) are primarily used in the course of thermal ablation of bone tumors. The first part of this review article describes the technical basics of the various thermoablative procedures; the second section discuses curative and palliative indications for thermal ablation of bone tumors.

\section{Thermoablative Procedures \\ $\nabla$}

Radiofrequency Ablation (RFA)

At present RFA is the most widespread and most thoroughly evaluated thermoablative procedure. This technique uses a $150-250$ watt generator to generate alternating current that oscillates between the radiofrequency (RF) electrode (cathode) inserted in the tumor and a neutral electrode on the body surface (unipolar system). When using a bipolar system, application of a neutral electrode is unnecessary, since the RF electrode functions as a cathode as well as an anode. While the current in this circuit oscillates in the tissue via ion channels, frictional processes at the tip of the RF electrode create heat (Joule effect), thereby destroying adjacent tumor tissue. The associated dehydration in the target tissue leads to an increase of tissue resistance during ablation thus limiting energy application, and the resulting ablation area exhibits limited expansion [3]. Depending on tumor size, quantity and location, one or more RF electrodes can be utilized; however, the electrodes may differ in design depending on the manufacturer (needle, umbrella or cluster electrodes) ( $\bullet$ Table 1 ). By additionally applying a temperature measurement probe, continuous monitoring of the tissue temperature can be performed during RFA as well as during MWA.

Internal cooling of the electrodes during ablation, as is possible with most of the available systems, thus guarantees more effective and homogeneous energy distribution. Particularly when compared to early MWA systems, RFA provides well reproducible necrosis zones. Additional technical implementations, such as the development of expandable probes (also called umbrella electrodes) to increase the electrode surface, application of pulsed energy as well as saline solution likewise contribute to producing homogeneous necrosis during RFA with predictable results.

\section{Microwave Ablation (MWA)}

During MWA a generator is used to produce a high-frequency electromagnetic field $(915 \mathrm{MHz}$ or $2.45 \mathrm{GHz}$ ) at the tip of the antenna inserted into the tumor. The result is interaction between the applied energy field and the intrinsic water dipoles in the adjoining tissue which have the tendency to arrange themselves continuously along the energy field. Rotation of the water molecules thereby generates kinetic energy and consequently frictional heat. MWA thus relies not on the flow of current, but rather on an electromagnetic field, and is thus largely independent of changes in tissue resistance. Consequently, compared to RFA, higher intratumoral temperatures $\left(>150^{\circ} \mathrm{C}\right)$ are achieved, associated with shortening of the ablation time and reduced heat loss in the tissue [4].

This is advantageous, particularly with respect to the previously-mentioned heat sink effect, a known phenomenon limiting the effectiveness of all thermoablative procedures. Blood vessels (diameter $\geq 3 \mathrm{~mm}$ ) that pass through the ablation zone or lie directly adjacent have a cooling effect, thus negatively affecting local heat transmission. As a consequence there can be incomplete ablation of tumor tissue adjoining these blood vessels with the risk of local tumor recurrence or progression. Current studies have shown that the heat sink effect is also present during MWA, although in reduced form compared to RFA, since this procedure directly heats a greater volume of tissue, and peripheral 
Table 1 Available systems for percutaneous tumor ablation.

\begin{tabular}{|c|c|c|c|}
\hline system & manufacturer & generator & applicator specifications \\
\hline \multicolumn{4}{|l|}{ RFA } \\
\hline AMICA-GEN & HS Amica & $\begin{array}{l}200 \mathrm{~W} ; 450 \mathrm{kHz}(+/-2.45 \mathrm{GHz}) \text {, dual } \\
\text { generator for RFA and MWA available) }\end{array}$ & unipolar, 17 G; active tip 10, 20 or 30 mm \\
\hline $1500 x$ & AngioDynamics & $250 \mathrm{~W} ; 460 \mathrm{kHz}$ & $\begin{array}{l}\text { unipolar; } 14 \mathrm{G}, 17 \mathrm{G} \text {; umbrella or needle electrode; } \\
\text { MRI-compatible electrode available }\end{array}$ \\
\hline RF 3000 & Boston Scientific & $200 \mathrm{~W} ; 480 \mathrm{kHz}$ & $\begin{array}{l}\text { unipolar; umbrella electrode array diameter: } \\
20 \text { - } 50 \mathrm{~mm} \text {; needle electrode: active tip } 9 \mathrm{~mm}\end{array}$ \\
\hline CoolTip E-Series & Covidien & $200 \mathrm{~W} ; 480 \mathrm{kHz}$ & $\begin{array}{l}\text { unipolar, } 17 \mathrm{G} \text {; active tip } 7-30 \mathrm{~mm} \text {; single or } \\
\text { cluster electrode }\end{array}$ \\
\hline STAR & DFINE & $10 \mathrm{~W} ; 480 \mathrm{kHz}$ & $\begin{array}{l}\text { bipolar; } 11 \mathrm{G} \text {, special for spine; angulated tip } \\
\text { max. } 41 \mathrm{~mm}\end{array}$ \\
\hline CelonLab POWER & Olympus & $250 \mathrm{~W} ; 470 \mathrm{kHz}$ & $\begin{array}{l}\text { bipolar; } 15 \mathrm{G} \text {; needle electrode; active tip: } \\
20-40 \mathrm{~mm} \text {; MRI-compatible electrode available }\end{array}$ \\
\hline \multicolumn{4}{|l|}{ MWA } \\
\hline AMICA-GEN & HS Amica & $\max .140 \mathrm{~W} ; 2.45 \mathrm{GHz}$ & $11,14,16 \mathrm{G}, \mathrm{max} .2$ antennas simultaneously \\
\hline Acculis & AngioDynamics & $\max .140 \mathrm{~W} ; 2.45 \mathrm{GHz}$ & $15 \mathrm{G}$; active tip: $28 \mathrm{~mm}$ \\
\hline Evident & Covidien & $45 \mathrm{~W} ; 915 \mathrm{kHz}$ & $\begin{array}{l}14 \text { G; active tip: } 20 \text { or } 37 \mathrm{~mm} \text {; max. } 3 \text { antennas } \\
\text { simultaneously }\end{array}$ \\
\hline Emprint & Covidien & $\max .100 \mathrm{~W} ; 2.45 \mathrm{GHz}$ & $13 \mathrm{G}$; active tip: $28 \mathrm{~mm}$ \\
\hline MicroThermX & Terumo & $\max .180 \mathrm{~W} ; 915 \mathrm{kHz}$ & $\begin{array}{l}14 \mathrm{G} \text {; active tip } 20 \text { or } 41 \mathrm{~mm} \text {; max. } 3 \text { antennas } \\
\text { simultaneously }\end{array}$ \\
\hline \multicolumn{4}{|l|}{ laser ablation } \\
\hline Medilas Fibertom 8100 & Dornier MedTech & $\begin{array}{l}100 \mathrm{~W} \text {; Nd:YAG laser; } \\
\text { wave length } 1064 \mathrm{~nm}\end{array}$ & $400 \mu \mathrm{m}, 600 \mu \mathrm{m}$ \\
\hline Model 25 & Diomed & $\begin{array}{l}25 \mathrm{~W} \text {; diode laser; } \\
\text { wave length } 805 \mathrm{~nm}\end{array}$ & $400 \mu \mathrm{m}$ \\
\hline \multicolumn{4}{|l|}{ cryoablation } \\
\hline PerCryo & Endocare (Healthtronics) & $\begin{array}{l}\text { argon for cooling, } \\
\text { helium for thawing }\end{array}$ & $\begin{array}{l}1.7-2.4 \mathrm{~mm} \text {; multiple probe configurations; } \\
\text { simultaneous ablation with up to max. } 8 \text { probes }\end{array}$ \\
\hline $\begin{array}{l}\text { Visual-ICE, Presice, } \\
\text { SeedNet, SeedNet MRI }\end{array}$ & Galil Medical & $\begin{array}{l}\text { argon for cooling, helium for } \\
\text { thawing; thawing process } \\
\text { possible without add. helium tank; } \\
\text { MRI-compatible system available }\end{array}$ & $\begin{array}{l}1.5 \text { or } 2.4 \mathrm{~mm} \text {; } 17 \mathrm{G} \text {; active tip up to } 47 \mathrm{~mm} \text { length; } \\
\text { multiple probe configurations; simultaneous abla- } \\
\text { tion with up to max. } 25 \text { probes }\end{array}$ \\
\hline \multicolumn{4}{|l|}{ MRgHIFU } \\
\hline ExAblate 2000 & InSightec & \multicolumn{2}{|c|}{ mobile patient table compatible only with general electric scanners ( 1.5 or $3 \mathrm{~T}$ ) } \\
\hline Sonalleve MR-HIFU & Philips Healthcare & \multicolumn{2}{|c|}{ mobile patient table compatible only with Phillips healthcare scanners ( 1.5 or $3 \mathrm{~T}$ ) } \\
\hline
\end{tabular}

RFA = Radiofrequency Ablation; MWA = Microwave Ablation, MRgHIFU = MR-guided High Intensity Focused Ultrasound.

heat transfer is less significant $[5,6]$. A further advantage over RFA is the fact that application of a neutral electrode is not required. Analogously to RFA, most available MWA systems provide internal cooling of the antennas during ablation thus providing more homogeneous energy distribution ( $\odot$ Table 1$)$. Furthermore, current studies have shown that in addition to RFA, MWA can be used on pacemaker patients without complication; however, close collaboration with a cardiologist is recommended in order to avoid malfunctions of the implant [7]. Compared to RFA, potential disadvantages of MWA particularly include higher material costs. Depending on the manufacturer, the wiring is relatively rigid and harder to handle. In addition, the antennas are often very flexible which can impede exact positioning during the procedure. Since during ablation of bone tumors, the lesion is generally first drilled and then the antenna is inserted coaxially, this latter aspect plays an important role primarily in the treatment of parenchymatous organs.

\section{Laser Ablation}

Laser ablation (formerly: laser-induced interstitial tumor therapy, LITT) is likewise a hyperthermal ablation proce- dure that is based on the effect of electromagnetic radiation with a wavelength in the near infrared range. Due to the good penetration qualities in the tissue, the most common energy sources are Nd:YAG (neodymium-doped yttrium aluminum garnet) or semiconductor conduction /diode lasers with a wavelength of $1064 \mathrm{~nm}$ or $800-1000 \mathrm{~nm}$ [8]. The photon-induced tissue heating, using the protein denaturing mechanism, results in coagulation necrosis and thus cell death. The very thin laser fibers $(200-600 \mu \mathrm{m})$ can be inserted into the tissue coaxially using an 18 gauge needle or via a special applicator system.

The size of the ablation zone during laser therapy depends on the size of the optical fiber, wavelength, thermal and optical characteristics of the tissue as well as the output and duration of the laser application [9]. Compared to other thermoablative procedures, the ablation volume generated by a single fiber is relatively small. Small bone lesions such as osteoid osteoma are therefore a very good indication for laser ablation. Several laser fibers can be simultaneously inserted to produce larger ablation zones. Likewise, internal cooling of the applicators prevents carbonization, thus leading to an enlargement of the ablation zone. The advantage is 
that the laser fibers do not interact with pacemakers or other metallic implants. Moreover, the MRI compatibility of the systems, as is also the case for individual RF systems ( $\odot$ Table 1), permits temperature monitoring during ablation while at the same time avoiding radiation exposure of the patients who are often young.

\section{High-intensity Focused Ultrasound (HIFU)}

High-intensity focused ultrasound (HIFU) is a comparatively new and non-invasive technique during which ultrasound waves with frequencies in the low megahertz range (17 MHz) are focused on a small target volume while neighboring organs and structures are spared. The mechanical energy of the sound wave is thus transformed into thermal energy, achieving temperatures above $90^{\circ} \mathrm{C}$. The ability to target tissue deep in the body depends on the frequency and intensity of the sound wave as well as the characteristics of the tissue lying between the piezoelectric transducer and target volume [10]. In addition to thermal damage in the target volume, the introduced ultrasonic pulse (sonication) causes mechanical effects, namely gas formation (cavitation effect). Due to this, brief pauses between individual sonications are necessary to avoid uncontrolled reflections and deformation of the ultrasound beam. A prerequisite for this is a free acoustic window, since gas, air and bone interfere with the propagation of the sound wave, as is already known from diagnostic ultrasound. Related border areas can absorb the sound wave with the risk of incomplete treatment of the tumor, cavitation effects as well as the hazard of burns to intervening tissue [9].

MR-guided HIFU (MRgHIFU) has been approved by the FDA and European Union for palliative treatment of bone lesions. Cortical bone is characterized by a high absorption of ultrasound and low thermal conductivity. This is an advantage in the treatment of painful bone metastases, since the maximum energy deposition occurs in the region of periosteal localized pain fibers [11]. On the whole, the procedure is quite time-consuming since the resulting ablation area is relatively small (between 50 and $300 \mathrm{~mm}^{3}$ ). Larger target volumes can be treated using a combination of several ablation areas [12]. Currently two MRgHIFU systems have been approved in Europe; however, they are compatible only with individual MRI devices ( $\bullet$ Table 1 ).

\section{Cryoablation}

In contrast with hyperthermal ablation procedures, during cryoablation, the tumor tissue is cooled to temperatures below $-20^{\circ} \mathrm{C}$. Energy transfer from the inserted probe into the surrounding tissue is achieved by means of conduction and convection, the latter mechanism among other things is dependent on heat transfer through adjacent blood vessels (counterpart to the heat sink effect, the so-called "cool sink" effect) [13]. The cryoablation probes have two chambers and are filled with compressed gases. Depending on the inversion temperature of the gases used, the JouleThomson effect results in a change in temperature as soon as the gases expand in the space surrounding the probe tip. For example, the inversion temperature of argon, nitrogen or oxygen is above room temperature such that when these gases expand, the temperature falls (cooling effect). The inversion temperature of hydrogen and helium is below room temperature; consequently the temperature rises as the gases expand [14]. Correspondingly, most clinical ablation systems employ compressed argon and helium for cooling and thawing, respectively; in such uses, temperatures below $-140{ }^{\circ} \mathrm{C}$ are achieved [15] ( $\bullet$ Table 1 ).

During ablation, the "ice ball" at the tip of the probe can be visualized directly, an advantage over other ablation techniques, for example during treatment of lesions adjoining critical structures (nerves, blood vessels) [16]. Whereas the diameter of the ice ball is essentially a function of the energy transfer rate (and thus dependent upon the flow rate of gas through the probe), the length of the ice ball is dependent upon the length of the non-insulated probe. It should be kept in mind that the boundary of the ice ball visible in the CT represents the $0{ }^{\circ} \mathrm{C}$ isotherm which is not lethal. In order to guarantee a complete ablation of the target lesion, the boundary of the ice ball should extend at least $5 \mathrm{~mm}$ beyond the lesion itself. Simultaneous application of multiple probes can correspondingly increase the ablation area [14]. A further advantage of cryoablation is its intrinsic analgesic effect which results in the patient experiencing less pain during and immediately after treatment compared to hyperthermal ablation techniques [16].

\section{Thermal Ablation of benign Bone Tumors Osteoid osteoma}

Osteoid osteoma is a bone-forming lesion, comprising about $10 \%$ of all bone tumors, primarily affecting children and youths between the ages of 10 and 25 years, with a predominance among males. Osteoid osteoma is histologically characterized by a central nidus made of osteoblasts and osteoid with peripheral nerve and vascular supply [17]. Excessive production of prostaglandins in the nidus results in local inflammatory response, hyperemia and abnormal bone growth [18]. Primary sites are the cortical long bones (primarily femur and tibia); approx. $10 \%$ of lesions are found in the axial skeleton, more rarely on the hands and feet. Clinically, osteoid osteoma is characterized by pain, occurring mainly at night, and typically responds to acetylsalicylic acid (ASA) or nonsteroidal anti-inflammatory drugs (NSAIDs). Depending on the location, there can be occurrences of stunting, bone deformity, painful scoliosis or muscle atrophy. Diagnosis is made based on clinical observation in combination with typical image-based findings ( $\bullet$ Fig. 2). Osteoid osteoma exhibits a very low tendency to grow. A conservative therapeutic approach with ASA or NSAIDs can provide simultaneous diagnostic indications. Prior to establishing minimally-invasive treatment procedures, surgical resection in the form of enbloc resection or curettage represents the primary mode of therapy with a success rate between 88 and $100 \%$. However, the invasiveness of these procedures involves complication rates of up to $35 \%$ (curettage) and $45.5 \%$ (resection) [19, 20]. Furthermore, the location in the bone of the generally small nidus can make surgery very difficult ( $\bullet$ Fig. 3 ).

Employing image-guided minimally-invasive treatment methods (CT-guided drilling, ablation) is advantageous both with respect to sparing adjacent structures as well as localizing the lesion during the procedure. CT-guided drilling of the nidus can be performed alone or in combination with an injection of ethanol. According to the literature, the success rate lies between 77 and $100 \%$; the complication rate is up to $24 \%$ [21]. However, recurrences are more fre- 

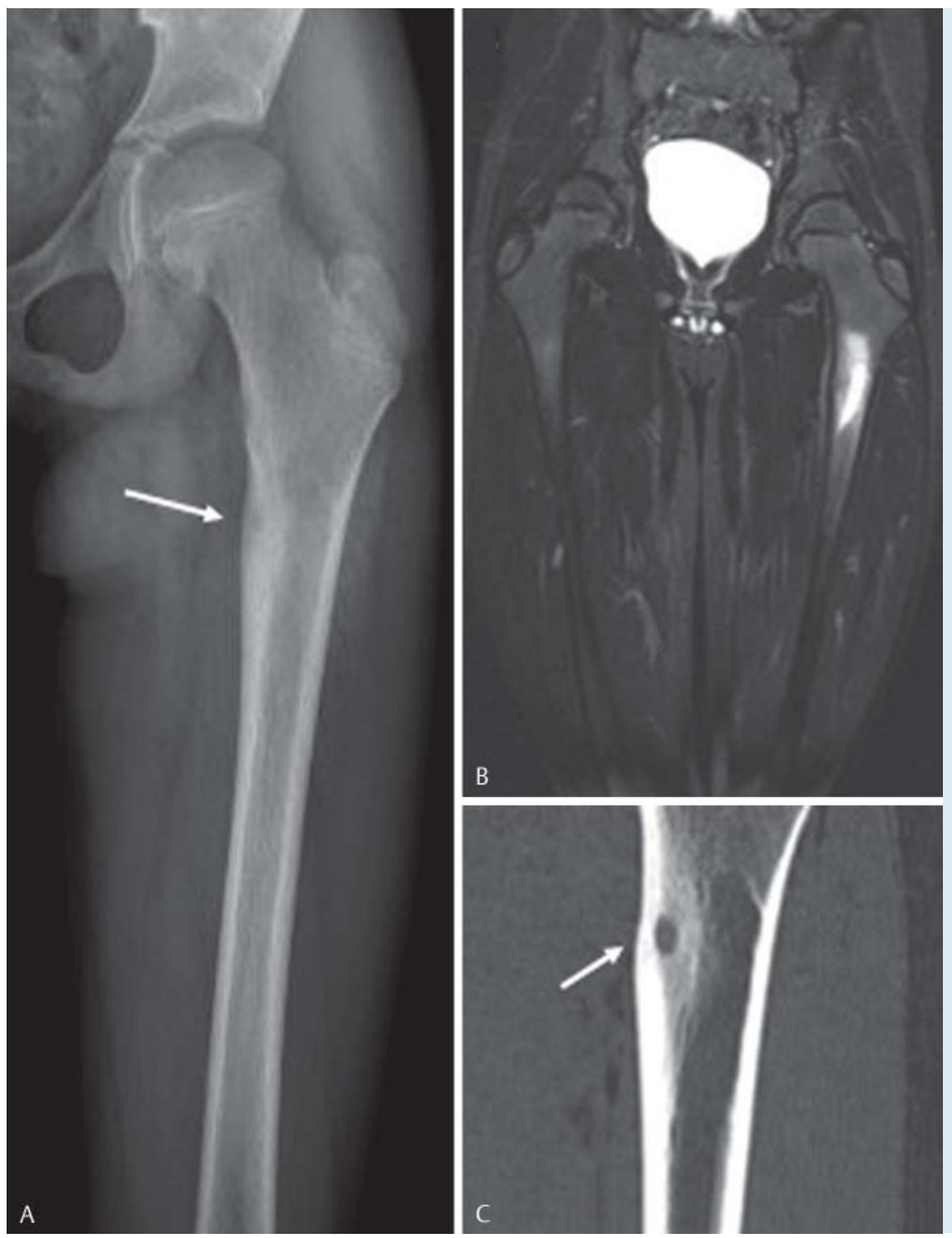

Fig. 2 10-year-old male patient with nocturnal pain in the left thigh and presentation of typical imaging findings consistent with osteoid osteoma. On plain radiography $\mathbf{A}$ a small lucent nidus (arrow) with surrounding sclerosis can be observed in the medial cortex. Coronal MRI (B, TIRM sequence) depicts marked bone marrow edema. The exact size of the nidus is best observed on CT (C, coronal reformation).

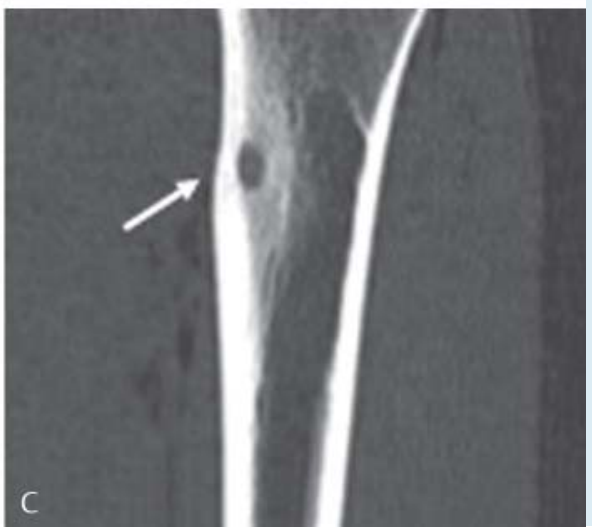

quent due to incomplete removal of the nidus. In addition, the alcohol distribution is more difficult to control which can result in damage to adjoining structures.

Nowadays, percutaneous thermal ablation, used to completely destroy the nidus, represents the method of choice for the treatment of osteoid osteoma (0 Fig.4). Since the patients are usually relatively young, the procedure is commonly performed under general anesthesia. Drilling the bone or nidus to place the applicators is performed manually employing coaxial systems or using an electric drill. Simultaneously, the diagnosis can be confirmed through biopsy; however biopsy is not necessary for diagnostic purposes, and depending on the size of the underlying study cohort, confirms the diagnosis only in $38-100 \%$ of cases $[22,23]$. The manufacturers' recommendations should be relied upon for the ablation protocol for the respective system. At our institution, we usually perform RFA under general anesthesia. Ablation is performed for 8 minutes at a target temperature of $80^{\circ} \mathrm{C}$ for unipolar RFA using a noncooled needle electrode. If the nidus is greater than $1 \mathrm{~cm}$, it is recommended to perform a second ablation cycle after an additional access path has been drilled with related repositioning of the applicator. Immediately after the procedure, pain symptoms may increase; therefore, good peri-interventional pain management is recommended. The patient can be mobilized directly after the procedure; success can be evaluated based on a clinical examination two weeks later. If symptoms persist or recur, repeated ablation is the method of choice; however the results of repeated ablation are usually worse in case of initial lack of symptoms. Relative contraindications for thermal ablation can depend on the location of the osteoid osteoma as well as the experience of the interventionist. Lesions in the region of the hand, feet or spinal column present special situations if they are located within less than $1 \mathrm{~cm}$ from vital structures (e.g. nerves). Injections of air, $\mathrm{CO} 2$ or glucose can separate critical structures, thereby increasing the safety during the procedure [24].

With respect to therapeutic success, the various thermoablative techniques are practically equal ( 0 Table 2 ). RFA provides the greatest evidence for ablation of osteoid osteoma; this procedure was first described in 1992 by Rosenthal 
Table 2 Overview of studies (selection) evaluating percutaneous thermal ablation methods for treating osteoid osteoma.

\begin{tabular}{|c|c|c|c|c|c|c|c|c|}
\hline technique & design & location & pat. [n] & PSR [\%] & SSR [\%] & compl. & FU & reference \\
\hline cryo & case report & extremities, thorax & 2 & 100 & & 0 & 20.5 months & Liu et al 2010 [51] \\
\hline cryo & retrospective & extremities & 6 & 100 & & 0 & 28.7 months & Wu et al 2011 [52] \\
\hline cryo & retrospective & extremities, pelvis & 10 & 100 & & 0 & 24 weeks & Coupal et al 2014 [31] \\
\hline laser & retrospective & extremities, spine, ribs & 114 & 95 & 99.1 & 1 & 58.5 months & Gangi et al 2007 [27] \\
\hline laser & retrospective & extremities (hand, foot) & 15 & 93.3 & 100 & 0 & 49.9 months & Zouari et al 2008 [53] \\
\hline laser & retrospective & extremities, pelvis, spine & 100 & 96 & 98 & 4 & 47 months & Roqueplan et al 2010 [54] \\
\hline laser & retrospective & extremities, pelvis & 35 & 94.3 & 97 & 4 & 40 months & Etienne et al 2013 [55] \\
\hline laser & retrospective & extremities, pelvis & 25 & 92 & n.a. & 5 & 26 months & Aschero et al 2009 [56] \\
\hline MRgFUS & retrospective & n.a. & 9 & 83 & & 0 & $1-3$ months & Napoli et al 2013 [57] \\
\hline MRgFUS & prospective & extremities & 29 & 90 & n.a. & 0 & 12 months & Geiger et al 2014 [30] \\
\hline MWA & retrospective & extremities (pineal) & 7 & 100 & & 0 & 8.6 months & Basile et al 2014 [28] \\
\hline MWA & retrospective & extremities, thorax & 10 & 100 & & 0 & 6 months & Kostrzewa et al 2014 [29] \\
\hline RFA & retrospective & extremities, pelvis, spine & 97 & 76 & 92 & 2 & 41 months & Vanderschueren et al 2002 [22] \\
\hline RFA & meta-analysis & extremities, pelvis, spine & 912 & 87 & 95 & 29 & n.a. & Bruners et al 2009 [26] \\
\hline RFA & retrospective & extremities & 557 & 96 & 99.6 & 5 & 3.5 years & Rimondi et al 2012 [58] \\
\hline RFA & retrospective & extremities, pelvis, spine & 263 & 89 & 91 & 2 & $>24$ months & Rosenthal et al 2013 [59] \\
\hline RFA & retrospective & extremities, pelvis, spine & 87 & 89.6 & 97.5 & 7 & 34 months & Bourgault et al 2014 [60] \\
\hline RFA & retrospective & $\begin{array}{l}\text { extremities, axial skele- } \\
\text { ton }\end{array}$ & 79 & 92 & 98.7 & 3 & 45.6 months & Own cohort \\
\hline
\end{tabular}

PSR = Primary Success Rate; SSR = Secondary Successse Rate ofter re-intervention; Compl. = Complications; FU = Average Follow-up; Cryo = Cryoablation, Laser = Laser Ablation; MRgFUS = MR-guided Focused UltrasoundSurgery; MWA = Microwave Ablation; RFA= Radiofrequency Ablation; n.a. = not indicated
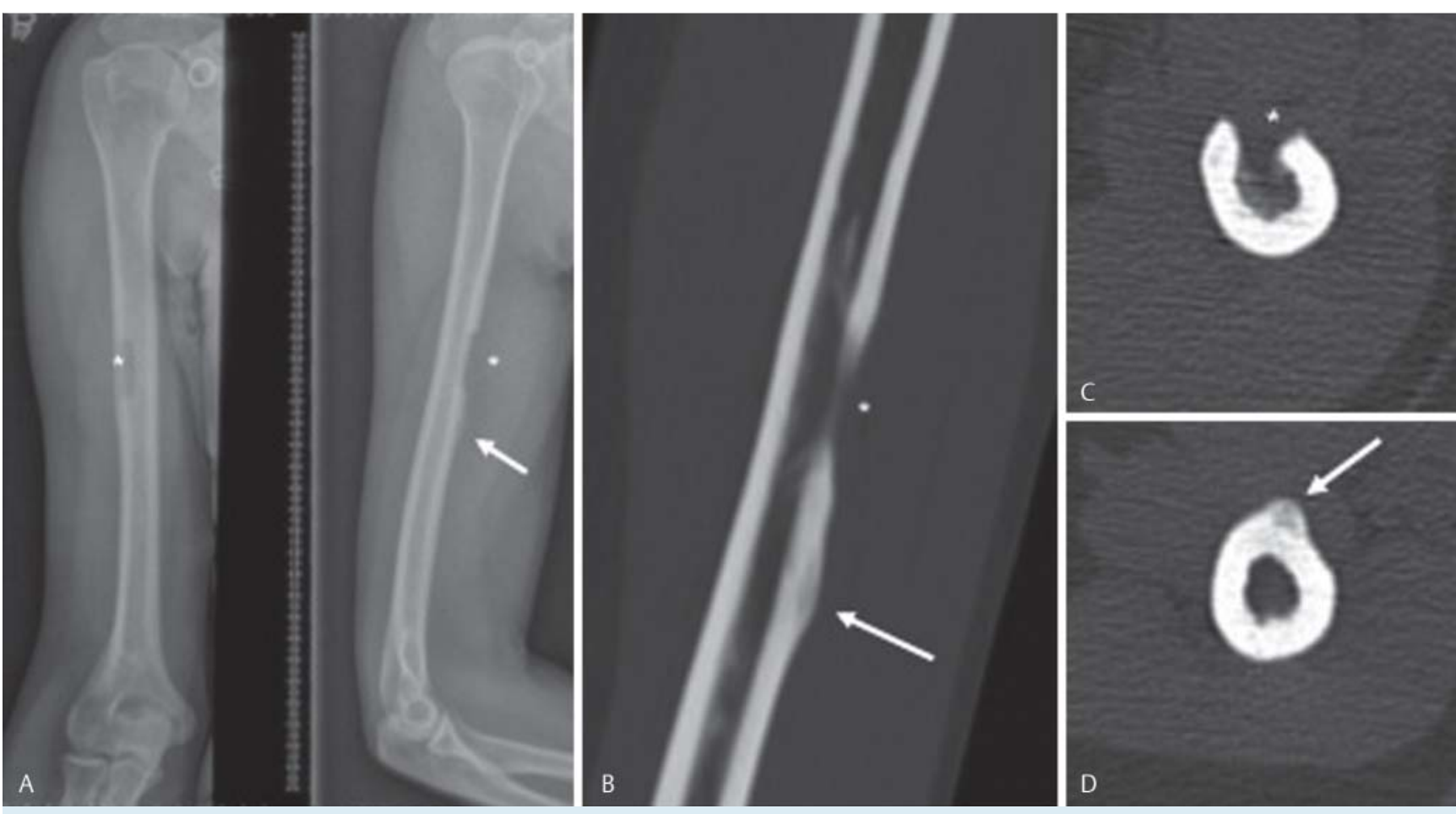

Fig. 3 47-year-old female patient with persistent pain in the right humerus three months following alleged resection of an osteoid osteoma. On postoperative radiography $\mathbf{A}$ the $\operatorname{defect}\left({ }^{*}\right)$ can be clearly visualized. The nidus (arrow) however is located further distal and has not been resected.
The patient was referred for RFA. On CT (periinterventional scan in the sagittal $\mathbf{B}$ and axial plane $\mathbf{C}, \mathbf{D})$ the nidus is clearly identified. The patient was free from pain following the day after the procedure. et al. [25]. The primary success rates indicated in the literature are $87-96 \%$. Overall success rates due to recurring symptoms lie between $91-99 \%$. Compared with all other procedures, the complication rate during percutaneous ablation is very low. In a systematic review article in 2009, out of 996 ablations, 29 complications were described, primarily involving burns, material breakage and local inflammatory response [26]. For laser ablation, the primary and secondary success rates are $92-96 \%$ and $97-100 \%$, respectively, comparable to those of RFA. Potential advantages of 

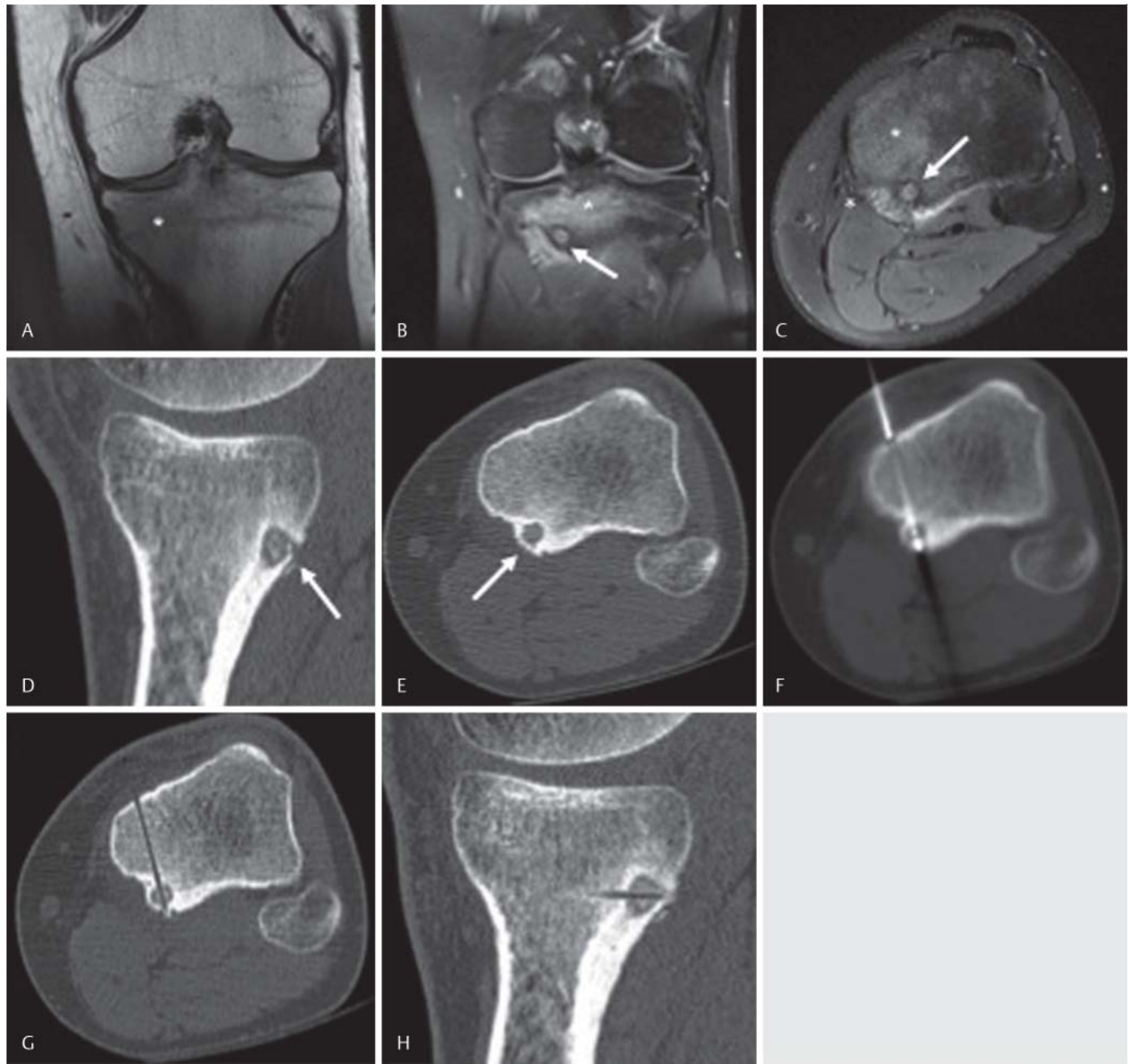

Fig. 4 22-year-old male patient with pain in the left lower leg independent of strain and lasting for about one year. MRI (coronal T1w A, coronal PDW B and axial PDw $\mathbf{C}$ ) depicts marked bone marrow edema. The nidus measures $7 \mathrm{~mm}$ and is located in the posterior cortex of the tibia. Peri-interventional

CT clearly presents the lesion (E, F, G: axial reformation; $\mathrm{D}, \mathrm{H}$ : sagittal reformation). The RFA probe is placed centrally in the nidus $\mathbf{F}$. On postinterventional $\mathrm{CT} \mathbf{G}, \mathbf{H}$ the bone access site can be appreciated. laser ablation can be shown for the treatment of lesions on small bones of the hands and feet due to the relative small path of access (18G) and good predictability of the resulting ablation zone [27]. When directly compared to RFA, MWA offers potential methodological and technical advantages that have been discussed at the beginning of this article; it can be presumed that the clinical results should be similar. However, there are to date only two studies in which a total of 17 patients have been treated using MWA [28, 29]. The situation is similar regarding studies of MRgHIFU treatment of osteoid osteoma. A prospective multi-center study describes a clinical success rate of $90 \%$ for this completely non-invasive procedure [30]. However, the authors of this study emphasize the importance of accurate localization of the lesion, since the general limitation of this method poses the risk of damage to adjoining neutral structures. Due to its intrinsic analgesic effect and the visualization characteristics of the ice ball during ablation, the use of cryoablation for treating osteoid osteoma is obvious. Intra- and post-operative pain is not as pronounced compared to e.g. RFA, so that treatment can also be performed under sedation [16, 31]. Interestingly, there have to date been no large-scale published studies demonstrating the long-term clinical success of cryoablation. 

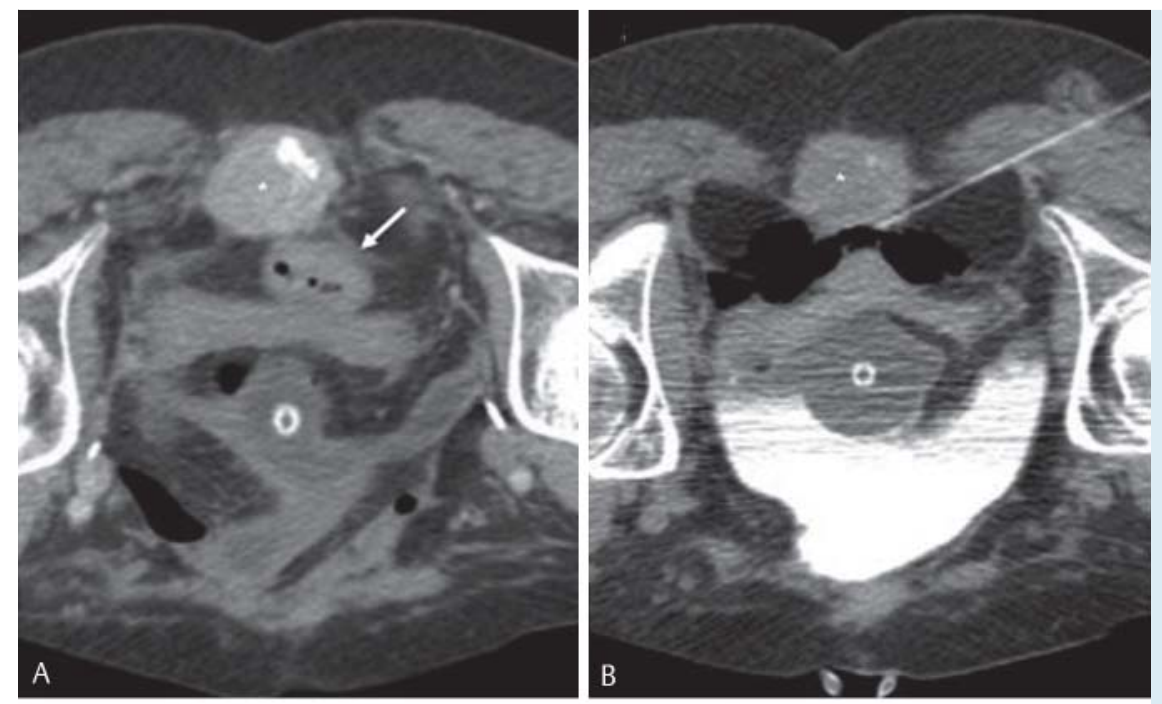

Fig. 5 60-year-old female patient with metastasized urothelial carcinoma. CT in the prone position with depiction of a contrastenhancing metastasis $\left({ }^{*}\right)$ in the sacral apex. As the patient had a neobladder percutaneous radiation therapy was not performed, and she was referred for MWA. The tumor is destroying the sacral bone as it is located in close proximity to the rectum (arrow in A). Using a $22 \mathrm{G}$ needle, $50 \mathrm{ml}$ of $\mathrm{CO}_{2}$ were injected into the perirectal fat tissue in order to displace the tumor from the rectum $\boldsymbol{B}$. Placement of the microwave antenna and ablation C. Immediately after the ablation a marked volume loss of the tumor can be observed $\mathbf{D}$. More importantly, the patient reported a significant and lasting reduction of pain: pre-interventional 8/10, 1 day post-intervention $6 / 10,4$ days post-intervention $3 / 10$ points on the visual analog scale.
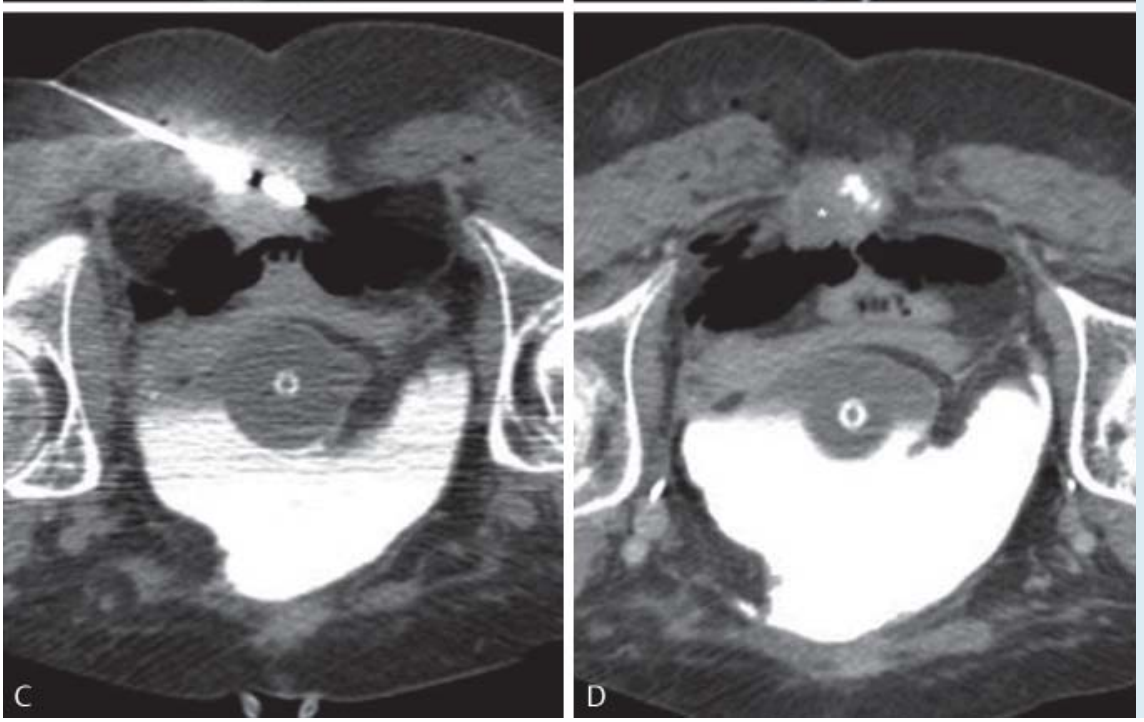

\section{Rare Indications}

Recently published studies indicated promising results, particularly for minimally-invasive treatment of osteoblastoma such that now RFA is currently regarded as the method of choice over surgical treatment [7, 32]. Experiences regarding percutaneous thermal ablation of other bone tumors are limited and rely mainly on case reports or small case series, examples of which include the treatment of chondroblastoma [33], eosinophilic granuloma [34] or desmoid tumors [35]. In individual cases, indication for this treatment can be provided due to a difficult local tumor situation, if surgical resection would involve extended damage to adjacent structures, for example [36], or if the patient refuses surgery. Indications for ablation in all cases should be provided after taking into account all interdisciplinary therapeutic alternatives.

\section{Thermal Ablation of malignant Bone Tumors Bone metastases}

The most frequent malignant bone tumors include metastases with primary tumor particularly of the breast, prostate or kidney. Pain as the cardinal symptom affects up to $80 \%$ of patients [37]. In this context, the long-term effects of un- treated, or insufficiently treated pain, should be kept in mind in addition to the acute symptoms. Such long-term effects particularly include limitations of mobility and reduced quality of life, anxiety and depression as well as the risk of pathological fracture [37]. Traditional therapeutic options for treating bone metastases include medicinal approaches, radiation and surgical procedures and depend on the tumor histology, quantity and location. Despite the availability of various therapeutic approaches, not all patients benefit equally from these treatment options. Among other things, varying radio sensitivity of different tumors and the latency period until the maximum effect of the treatment sets in should be kept in mind [38]. Surgical alternatives are invasive and, depending upon location and the tumor, involve a high morbidity rate and long postoperative hospitalization [39]. There are therapeutic shortcomings in the general concept of the treatment of bone metastases.

Initial, mainly retrospective studies have described excellent clinical results for percutaneous thermal ablation of bone metastases. For example, Thanos et al. could achieve pain reduction in 19 of 30 patients within 24 hours after RFA. Within a week, all patients reported significant pain 

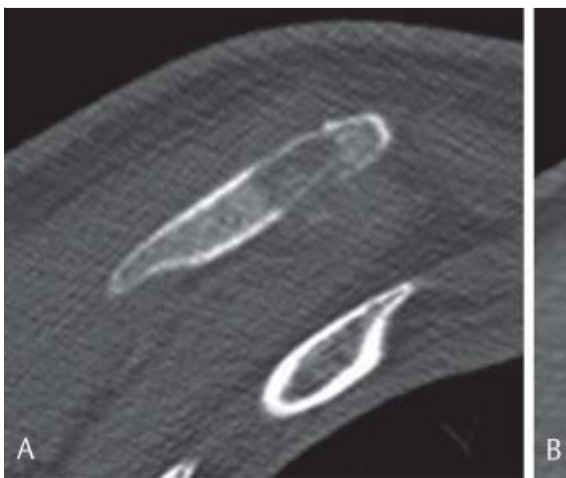

Fig. 6 40-year-old male patient with metastasized angiosarcoma and severe pain in the left scapula. $\mathrm{CT}$ in the prone position with depiction of an osteolysis in the inferior angle $\mathbf{A}$ and placed microwave antenna $\mathbf{B}$. Pain course on the visual analog scale $\mathbf{C}$. Immediately after the procedure the
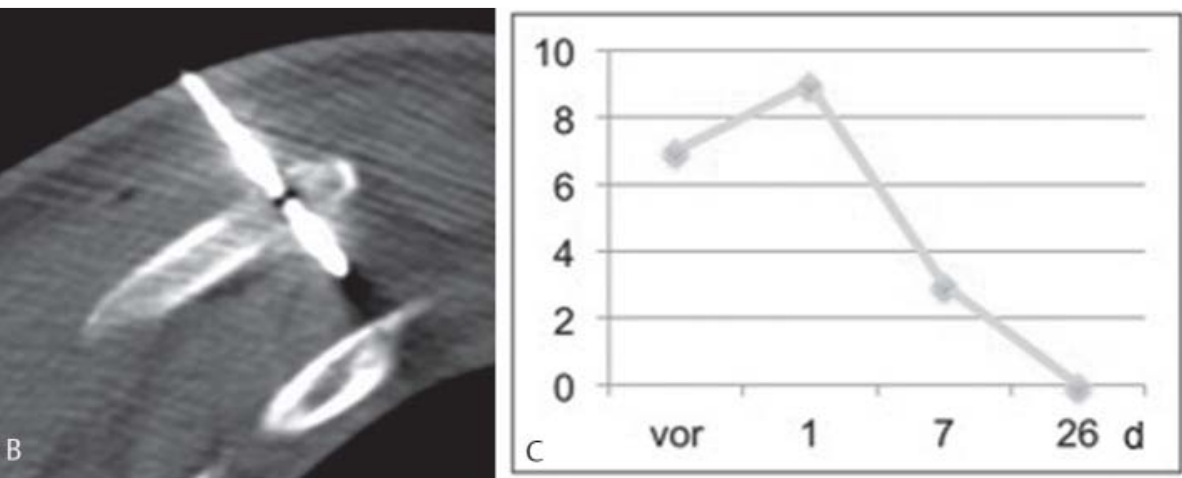

patient reported a temporal increase of pain which declined afterwards. 26 days following the intervention, the patient was free from pain at this location.
Table 3 Patient selection criteria for palliative percutaneous thermal ablation of painful bone metastases (adapted from [41]).

\begin{tabular}{|c|c|}
\hline inclusion criteria & exclusion criteria \\
\hline localizable pain $>4$ / 10 on the VAS & disseminated painful metastases \\
\hline $\begin{array}{l}\text { max. two dominant pain locations } \\
\text { due to bone metastases }\end{array}$ & risk of fracture of target bone \\
\hline life expectancy $>2$ months & (osteoblastic metastases) \\
\hline capable of agreeing to procedure & $\begin{array}{l}\text { (lesion }<1 \mathrm{~cm} \text { distant from critical } \\
\text { structures) }\end{array}$ \\
\hline $\begin{array}{l}\text { coagulation (PTT < } 50 \mathrm{~s} \text {, Quick } \\
>50 \% \text {, platelets }>5000 / \mu \mathrm{l} \text { ) }\end{array}$ & \\
\hline
\end{tabular}

VAS = Visual Analog Scale; PTT = Partial Thromboplastin Time.

reduction, together with an improvement of their quality of life [40]. The effect of ablation to achieve immediate pain reduction is based on thermal destruction of pain fibers and receptors, tumor cell destruction as well as reduced secretion of osteoclast-activating factors (e. g. interleukins, TNF$\alpha$, endothelins). In this regard, the primary goal of percutaneous thermal ablation is palliation of pain via targeted treatment of the boundary surfaces between the tumor and bone ( $\Theta$ Fig. 5). Tumor debulking, i. e., mass reduction, is only a secondary consideration. Since there may be an initial increase in pain symptoms immediately after treatment, sufficient peri- and post-interventional pain management should be employed, using a PCA pump if needed (o Fig. 6).

Patient selection for effective treatment of bone metastases should be performed critically [41] ( $(0$ Table 3 ). The most suitable patients are those indicating pain greater than 4 points on the 10-point visible analog scale (VAS), but with no more than two predominant pain locations. The treatment of osteolytic metastases in weight-bearing regions can be combined with cementoplasty to minimize the risk of pathological fracture. Less suitable are patients with disseminated painful metastases. Lesions with the risk of fracture should primarily undergo surgical therapy. Tumors with a distance less than $1 \mathrm{~cm}$ from critical structures such as the spinal cord or large blood vessels represent a relative contraindication, if it is not possible to isolate these structures via protective means (e.g. air, $\mathrm{CO} 2$ or glucose). In most studies, osteoblastic metastases have not been shown to be suitable, even though treatment can be successful in individual cases $[42,43]$.

In the meantime, the literature provides clear evidence that ablation of painful bone metastases effectively contributes to pain reduction. Analogously to the treatment of benign bone lesions, the various thermoablative techniques are comparable with respect to their result ( $\odot$ Table 4 ); the advantages and disadvantages of the individual procedures discussed in the previous sections likewise apply. Thus, for example, cryoablation, when directly compared to RFA, shows potential advantages with respect to the direct postinterventional pain symptoms [44]. Guglielmi et al. compared effectiveness of cryoablation plus cementoplasty with RFA plus cementoplasty in the treatment of 30 osteolytic bone metastases [45]. With respect to the therapeutic result measured by means of the visual analog scale, no significant difference was found in the time frame of one week to six months after the treatment. However, the immediate treatment-associated pain in the early post-interventional phase was less pronounced after ablation. In this context using only cement injection or vertebroplasty can be expedient. The synergistic chemical, thermal and mechanical effects of the injected cement (generally polymethylmethacrylate, PMMA) can result in significant reduction of pain in patients with osteolytic metastases of the spine [46]. However, most studies indicate that a longer-lasting benefit resulted from combinational therapy, e.g. cryoablation plus vertebroplasty [47]. The supplemental injection of cement offers the advantage of immediate stabilization.

\section{Rare Indications}

The treatment of primary malignant bone tumors is principally surgical, with accompanying systemic therapy as needed. An interdisciplinary approach can employ percutaneous ablation, such as in the case of lesions that are located in anatomically unfavorable sites, inoperability or recurrence. Evidence in the literature regarding the effectiveness in selected cohorts is limited in this respect, however. For example, Yamakado et al. performed RFA on 52 patients with recurrent osteo- or soft tissue sarcoma; in $40.4 \%$ of these cases complete ablation was achieved [48]. The 
Table 4 Studies (selection) evaluating percutaneous thermal ablation methods for treatment of painful bone metastases.

\begin{tabular}{|c|c|c|c|c|c|c|}
\hline technique & design & metastases & location & lesions [n] & conclusions & reference \\
\hline cryo & prospective & osteolytic & extremities, thorax, pelvis & 18 & effective pain reduction & Callstrom et al 2006 [42] \\
\hline cryo & $\begin{array}{l}\text { prospective, } \\
\text { multicenter }\end{array}$ & osteolytic & $\begin{array}{l}\text { extremities, thorax, spine, } \\
\text { pelvis }\end{array}$ & 69 & effective pain reduction & Callstrom et al 2013 [61] \\
\hline cryo + cement & retrospective & mixed & extremities, spine & 48 & $\begin{array}{l}\text { curative treatment possible in } \\
\text { individual cases }\end{array}$ & Deschamps et al 2014 [62] \\
\hline MRgHIFU & retrospective & mixed & extremities, pelvis & 13 & effective pain reduction & Catane et al 2007 [11] \\
\hline MRgHIFU & multicenter & mixed & extremities, pelvis & 32 & safe and effective pain reduction & Liberman et al 2009 [63] \\
\hline MRgHIFU & $\begin{array}{l}\text { prospective, } \\
\text { multicenter }\end{array}$ & mixed & $\begin{array}{l}\text { extremities, thorax, spine, } \\
\text { pelvis }\end{array}$ & 112 & $\begin{array}{l}\text { safe and effective pain reduction } \\
\text { compared to placebo group }\end{array}$ & Hurwitz et al 2014 [64] \\
\hline MWA & retrospective & mixed & thorax, spine & 19 & effective pain reduction & Kastler et al 2013 [65] \\
\hline MWA + cement & retrospective & osteolytic & extraspinal & 33 & $\begin{array}{l}\text { safe and effective pain reduction } \\
\text { for bronchial Ca metastases }\end{array}$ & Wei et al 2015 [66] \\
\hline MWA + cement & retrospective & osteolytic & $\begin{array}{l}\text { extremities, spine, } \\
\text { pelvis }\end{array}$ & 37 & $\begin{array}{l}\text { pain reduction for all patients } \\
\text { within one week }\end{array}$ & Pusceddu et al 2015 [67] \\
\hline RFA & $\begin{array}{l}\text { prospective, } \\
\text { multicenter }\end{array}$ & osteolytic & $\begin{array}{l}\text { extremities, thorax, spine, } \\
\text { pelvis }\end{array}$ & 43 & effective pain palliation & Goetz et al 2004 [68] \\
\hline RFA & $\begin{array}{l}\text { prospective, } \\
\text { multicenter }\end{array}$ & n.a. & $\begin{array}{l}\text { extremities, thorax, spine, } \\
\text { pelvis }\end{array}$ & 55 & effective and safe pain palliation & Dupuy et al 2010 [69] \\
\hline RFA + cement & retrospective & mixed & extremities, spine & 74 & $\begin{array}{l}\text { curative treatment possible in } \\
\text { individual cases }\end{array}$ & Deschamps et al 2014 [62] \\
\hline
\end{tabular}

Cryo = Cryoablation; Laser = Laser Ablation; MRgHIFU = MR-guided High Intensity Focused Ultrasound; MWA = Microwave Ablation; RFA= Radiofrequency Ablation; n.a. = not specified.

overall survival rate after 1,3 and 5 years was $73.4 \%, 39.3 \%$ and $34.4 \%$, respectively. Using ultrasound-guided HIFU, Chen et al. treated 80 patients with bone tumors (osteosarcoma, chondrosarcoma, Ewing sarcoma, giant cell tumor). [49]. In combination with systemic chemotherapy, the survival of patients with stage $2 \mathrm{~b}$ tumor disease was thereby significantly improved. In addition to individual case reports in the literature such as the treatment of aneurysmal bone cysts or giant cell tumors, when pain is in the forefront of symptoms, percutaneous ablation can additionally be employed in the palliation of primary bone tumors, analogously to the treatment of bone metastases [50].

\section{Summary}

Various techniques can be used for percutaneous thermal ablation of bone tumors, each of which offers specific advantages and disadvantages. Percutaneous ablation is the therapy of choice for the treatment of osteoid osteoma, due to the relatively lower complication rate, shorter rehabilitation time and lower costs, combined with a very high success rate, when compared to surgery. Percutaneous ablation of bone metastases for palliation of pain is effective and should be integrated into existing therapeutic concepts. The effectiveness of ablation is less dependent on the size of the lesion, but rather should be related to the specific indication, which should be limited to patients with welllocalized pain. Indications for treatment of other benign and malignant bone tumors are present in individual cases due to a tumor-specific situation and should be reviewed by an interdisciplinary tumor board.

\section{References}

1 Ahmed M, Solbiati L, Brace CL et al. Image-guided tumor ablation: standardization of terminology and reporting criteria - a 10-year update. Radiology 2014; 273: 241 - 260

2 Goldberg SN, Gazelle GS, Mueller PR. Thermal ablation therapy for focal malignancy: a unified approach to underlying principles, techniques, and diagnostic imaging guidance. Am J Roentgenol 2000; 174: $323-331$

3 Hong K, Georgiades CS. Radiofrequency Ablation: Mechanism of Action and Devices. In: Hong K, Georgiades CS (eds) Percutaneous Tumor Ablation. edn. New York: Thieme; 2011: 1-14

4 Brace CL, Laeseke PF, Sampson LA et al. Microwave ablation with multiple simultaneously powered small-gauge triaxial antennas: results from an in vivo swine liver model. Radiology 2007; 244: 151 - 156

5 Wright AS, Sampson LA, Warner TF et al. Radiofrequency versus microwave ablation in a hepatic porcine model. Radiology 2005; 236: 132 139

6 Ringe KI, Lutat C, Rieder C et al. Experimental Evaluation of the Heat Sink Effect in Hepatic Microwave Ablation. PloS one 2015; 10: e0134301

7 Skonieczki BD, Wells C, Wasser EJ et al. Radiofrequency and microwave tumor ablation in patients with implanted cardiac devices: is it safe? Eur J Radiol 2011; 79: 343 - 346

8 Vogl TJ, Mack M, Straub R et al. Percutaneous interstitial thermotherapy of malignant liver tumors. Fortschr Röntgenstr 2000; 172: 12 -22

9 Garnon J, Tsoumakidou G, Enescu J et al. Overview of thermal ablation devices: HIFU, laser interstitial, chemical ablation. In: Clark $T$, Sabhawal T (eds) Interventional Radiology Techniques in Ablation. London: Springer; 2013: 29-37

10 Avedian RS, Gold G, Ghanouni P et al. Magnetic resonance guided highintensity focused ultrasound ablation of musculoskeletal tumors. Curr Orthop Pract 2011; 22: 303-308

11 Catane R, Beck A, Inbar $Y$ et al. MR-guided focused ultrasound surgery (MRgFUS) for the palliation of pain in patients with bone metastases preliminary clinical experience. Ann Oncol 2007; 18: 163-167

12 Jenne JW, Preusser T, Gunther M. High-intensity focused ultrasound: principles, therapy guidance, simulations and applications. ZMed Phys 2012; 22: 311-322

13 Kim C, O'Rourke AP, Mahvi DM et al. Finite-element analysis of ex vivo and in vivo hepatic cryoablation. IEEE Trans Biomed Eng 2007; 54: $1177-1185$ 
14 Georgiades CS, Marx JK. Cryoablation: Mechanism of Action and Devices. In: Hong K, Georgiades CS (eds) Percutaneous Tumor Ablation. New York: Thieme; 2011: 15-26

15 Isfort P, Penzkofer T, Mahnken AH. Cryoablation - back again? Radiologe 2012; 52: 29-37

16 Callstrom MR, Kurup AN. Percutaneous ablation for bone and soft tissue metastases-why cryoablation? Skelet Radiol 2009; 38: 835 - 839

17 Motamedi D, Learch TJ, Ishimitsu DN et al. Thermal ablation of osteoid osteoma: overview and step-by-step guide. Radiographics 2009; 29: $2127-2141$

18 Greco F, Tamburrelli F, Ciabattoni G. Prostaglandins in osteoid osteoma. Int Orthop 1991; $15: 35-37$

19 Cantwell CP, Obyrne J, Eustace S. Current trends in treatment of osteoid osteoma with an emphasis on radiofrequency ablation. Eur Radiol 2004; 14: $607-617$

20 Sluga $M$, Windhager $R$, Pfeiffer $M$ et al. Peripheral osteoid osteoma. Is there still a place for traditional surgery? J Bone Joint Surg Br 2002; 84: $249-251$

21 Parlier-Cuau C, Champsaur P, Nizard $R$ et al. Percutaneous removal of osteoid osteoma. Radiol Clin North Am 1998; 36: 559-566

22 Vanderschueren GM, Taminiau AH, Obermann WR et al. Osteoid osteoma: clinical results with thermocoagulation. Radiology 2002; 224: $82-86$

23 Rosenthal DI, Springfield DS, Gebhardt MC et al. Osteoid osteoma: percutaneous radio-frequency ablation. Radiology 1995; 197: 451 - 454

24 Rybak LD, Gangi A, Buy X et al. Thermal ablation of spinal osteoid osteomas close to neural elements: technical considerations. Am J Roentgenol 2010; 195: W293-W298

25 Rosenthal DI, Alexander A, Rosenberg AE et al. Ablation of osteoid osteomas with a percutaneously placed electrode: a new procedure. Radiology 1992; 183: 29-33

26 Bruners P, Penzkofer T, Gunther RW et al. Percutaneous radiofrequency ablation of osteoid osteomas: technique and results. Fortschr Röntgenstr 2009; 181: $740-747$

27 Gangi A, Alizadeh H, Wong L et al. Osteoid osteoma: percutaneous laser ablation and follow-up in 114 patients. Radiology 2007; 242: 293 - 301

28 Basile A, Failla G, Reforgiato A et al. The use of microwaves ablation in the treatment of epiphyseal osteoid osteomas. Cardiovasc Intervent Radiol 2014: 37: 737 - 742

29 Kostrzewa M, Diezler P, Michaely H et al. Microwave ablation of osteoid osteomas using dynamic MR imaging for early treatment assessment: preliminary experience. J Vasc Intervent Radiol 2014; 25: 106-111

30 Geiger D, Napoli A, Conchiglia A et al. MR-guided focused ultrasound (MRgFUS) ablation for the treatment of nonspinal osteoid osteoma: a prospective multicenter evaluation. J Bone Joint Surg Am 2014; 96: $743-751$

31 Coupal TM, Mallinson PI, Munk PL et al. CT-guided percutaneous cryoablation for osteoid osteoma: initial experience in adults. Am J Roentgenol 2014; 202: 1136-1139

32 Weber MA, Sprengel SD, Omlor GW et al. Clinical long-term outcome, technical success, and cost analysis of radiofrequency ablation for the treatment of osteoblastomas and spinal osteoid osteomas in comparison to open surgical resection. Skelet Radiol 2015; 44: 981 - 993

33 Erickson JK, Rosenthal DI, Zaleske DJ et al. Primary treatment of chondroblastoma with percutaneous radio-frequency heat ablation: report of three cases. Radiology 2001; 221: $463-468$

34 Corby RR, Stacy GS, Peabody TD et al. Radiofrequency ablation of solitary eosinophilic granuloma of bone. Am J Roentgenol 2008; 190: $1492-1494$

35 Kujak JL, Liu PT, Johnson GB et al. Early experience with percutaneous cryoablation of extra-abdominal desmoid tumors. Skeletal Radiol 2010; 39: 175-182

36 Ringe KI, Rosenthal $H$, Langer $F$ et al. Radiofrequency ablation of a rare case of an intraosseous hibernoma causing therapy-refractory pain. J Vasc Intervent Radiol 2013; 24: 1754-1756

37 Janjan NA, Payne R, Gillis T et al. Presenting symptoms in patients referred to a multidisciplinary clinic for bone metastases. J Pain Symptom Manage 1998; 16: 171 - 178

38 Lin A, Ray ME. Targeted and systemic radiotherapy in the treatment of bone metastasis. Cancer Metastasis Rev 2006; 25: 669-675

39 Manabe J, Kawaguchi N, Matsumoto $S$ et al. Surgical treatment of bone metastasis: indications and outcomes. Int J Clin Oncol 2005; 10: $103-111$

40 Thanos L, Mylona S, Galani P et al. Radiofrequency ablation of osseous metastases for the palliation of pain. Skelet Radiol 2008; 37: 189-194
41 Brown DB. Musculoskeletal Ablation. In: Hong K, Georgiades C (eds) Percutaneous Tumor Ablation. New York: Thieme; 2011: 137-152

42 Callstrom MR, Atwell TD, Charboneau JW et al. Painful metastases involving bone: percutaneous image-guided cryoablation - prospective trial interim analysis. Radiology 2006; 241: 572 - 580

43 Breckheimer A, Bruners P, Mahnken A. Interventional management of a rare complication in radiofrequency ablation of an osteosclerotic bone metastasis. Fortschr Röntgenst 2010; 182: 433 -435

44 Thacker PG, Callstrom MR, Curry TB et al. Palliation of painful metastatic disease involving bone with imaging-guided treatment: comparison of patients' immediate response to radiofrequency ablation and cryoablation. Am J Roentgenol 2011; 197: 510-515

45 Masala S, Guglielmi G, Petrella MC et al. Percutaneous ablative treatment of metastatic bone tumours: visual analogue scale scores in a short-term series. Singapore Med J 2011; 52: 182 - 189

46 Andreula $C$, Muto $M$, Leonardi $M$. Interventional spinal procedures. Eur J Radiol 2004; 50: 112 -119

47 Masala S, Chiocchi M, Taglieri A et al. Combined use of percutaneous cryoablation and vertebroplasty with 3D rotational angiograph in treatment of single vertebral metastasis: comparison with vertebroplasty. Neuroradiology 2013; 55: $193-200$

48 Yamakado K, Matsumine A, Nakamura T et al. Radiofrequency ablation for the treatment of recurrent bone and soft-tissue sarcomas in nonsurgical candidates. Int J Clin Oncol 2014; 19: 955-962

49 Chen W, Zhu H, Zhang L et al. Primary bone malignancy: effective treatment with high-intensity focused ultrasound ablation. Radiology 2010; 255: 967 - 978

50 Rybak LD, Rosenthal DI, Wittig JC. Chondroblastoma: radiofrequency ablation-alternative to surgical resection in selected cases. Radiology 2009; 251: 599-604

51 Liu DM, Kee ST, Loh CT et al. Cryoablation of osteoid osteoma: two case reports. J Vasc Intervent Radiol 2010; 21: 586-589

52 Wu B, Xiao YY, Zhang X et al. CT-guided percutaneous cryoablation of osteoid osteoma in children: an initial study. Skelet Radiol 2011; 40 $1303-1310$

53 Zouari L, Bousson V, Hamze B et al. CT-guided percutaneous laser photocoagulation of osteoid osteomas of the hands and feet. Eur Radiol 2008; 18: 2635 - 2641

54 Roqueplan F, Porcher $R$, Hamze $B$ et al. Long-term results of percutaneous resection and interstitial laser ablation of osteoid osteomas. Eur Radiol 2010; 20: 209-217

55 Etienne A, Waynberger E, Druon J. Interstitial laser photocoagulation for the treatment of osteoid osteoma: retrospective study on 35 cases. Diagn Interv Imaging 2013; 94: 300 - 310

56 Aschero A, Gorincour G, Glard Y et al. Percutaneous treatment of osteoid osteoma by laser thermocoagulation under computed tomography guidance in pediatric patients. Eur Radiol 2009; 19: 679-686

57 Napoli A, Anzidei M, Ciolina F et al. MR-guided high-intensity focused ultrasound: current status of an emerging technology. Cardiovasc Intervent Radiol 2013; 36: 1190-1203

58 Rimondi E, Mavrogenis AF, Rossi G et al. Radiofrequency ablation for non-spinal osteoid osteomas in 557 patients. Eur Radiol 2012; 22: $181-188$

59 Rosenthal DI, Hornicek FJ, Torriani M et al. Osteoid osteoma: percutaneous treatment with radiofrequency energy. Radiology 2003; 229: $171-175$

60 Bourgault C, Vervoort T, Szymanski C et al. Percutaneous CT-guided radiofrequency thermocoagulation in the treatment of osteoid osteoma: a 87 patient series. Orthop Ttraumatol Surg Res 2014; 100: $323-327$

61 Callstrom MR, Dupuy DE, Solomon SB et al. Percutaneous image-guided cryoablation of painful metastases involving bone: multicenter trial. Cancer 2013; 119: 1033-1041

62 Deschamps F, Farouil $G$, Ternes $N$ et al. Thermal ablation techniques: a curative treatment of bone metastases in selected patients? Eur Radiol 2014; 24: 1971 - 1980

63 Liberman B, Gianfelice D, Inbar Y et al. Pain palliation in patients with bone metastases using MR-guided focused ultrasound surgery: a multicenter study. Ann Surg Oncol 2009; 16: 140-146

64 Hurwitz MD, Ghanouni P, Kanaev SV et al. Magnetic resonance-guided focused ultrasound for patients with painful bone metastases: phase III trial results. J Natl Cancer Inst 2014; 106

65 Kastler A, Alnassan H, Pereira PL et al. Analgesic effects of microwave ablation of bone and soft tissue tumors under local anesthesia. Pain Med 2013; 14: 1873 - 1881 
66 Wei Z, Zhang K, Ye X et al. Computed tomography-guided percutaneous microwave ablation combined with osteoplasty for palliative treatment of painful extraspinal bone metastases from lung cancer. Skelet Radiol 2015; 44: 1485-1490

67 Pusceddu C, Sotgia B, Fele RM et al. Combined Microwave Ablation and Cementoplasty in Patients with Painful Bone Metastases at High Risk of Fracture. Cardiovasc Intervent Radiol 2015, Jun 13 [epub ahead of print]
68 Goetz MP, Callstrom MR, Charboneau JW et al. Percutaneous imageguided radiofrequency ablation of painful metastases involving bone: a multicenter study. J Clin Oncol 2004; 22: 300 - 306

69 Dupuy DE, Liu D, Hartfeil D et al. Percutaneous radiofrequency ablation of painful osseous metastases: a multicenter American College of Radiology Imaging Network trial. Cancer 2010; 116: 989-997 